\title{
Laser-Welding of a Ni-Rich TiNi Shape Memory Alloy: Mechanical Behavior
}

\author{
P. Schlossmacher, T. Haas and A. Schüssler( $\left.{ }^{1}\right)$ \\ Forschungszentrum Karlsruhe, Institute of Materials Research I, P.O. Box 3640, 76021 Karlsruhe, \\ Germany
}

\begin{abstract}
A Nd:YAG laser was used for joining a pseudoelastic Ti-51.5 at.\% Ni shape memory alloy. Tensile tests on sheet metal of $0.5 \mathrm{~mm}$ thickness were performed at temperatures of $-40^{\circ} \mathrm{C},+20^{\circ} \mathrm{C}$ and $110^{\circ} \mathrm{C}$, representing the martensitic, pseudoelastic and austenitic condition, respectively. Laser-welded specimens exhibited an ultimate tensile strength of about $820 \mathrm{MPa}$ not affected by the test temperature. This value corresponds to $80 \%$ of the ultimate tensile strength of the base material which was also tested in its martensitic, pseudoelastic and austenitic condition. Therefore, the full use of stress-induced martensite formation on welded components is ensured.

However, for a comprehensive understanding of microstructural changes resulting from laser-welding investigations of the $0.6 \mathrm{~mm}$ weld were carried out by optical and transmission electron microscopy. Their results will be presented and discussed with respect to the tensile tests. Observation of fracture surfaces of ruptured specimens by scanning electron microscopy confirmed the ductile behavior of laser-welded joints.
\end{abstract}

\section{INTRODUCTION}

Up to now only a few experiments concerning joining techniques for TiNi shape memory alloys (SMAs) are reported in the literature [1-6]. Mainly two routes were followed: friction welding [1,2] and resistance butt-welding [3-5]. Both methods have in common that they can be performed at ambient atmosphere. A high upset force compressing the two work-pieces against each other leads to an outward extrusion of the fusion zone and oxidation is mainly prevented. The two major disadvantages of these methods are: (i) there is a strong restriction to geometries with rotational symmetry, and (ii) the welding zones have to be trimmed due to the strong extrusion of matter.

To our knowledge the sole investigations using laser beam technology for joining a TiNi SMA was performed using a $\mathrm{CO}_{2}$ laser [7,8]. Tensile strength of about $34 \%$ and $~ 60 \%$ of the unwelded material, a Ti-50.7at.\%Ni alloy, were reported for the martensitic $\left(-40^{\circ} \mathrm{C}\right)$ and pseudoelastic condition $\left(+40^{\circ} \mathrm{C}\right)$, respectively. Preservation of shape memory properties and pseudoelastic behavior were stated without experimental proof.

In order to investigate the weldability of binary TiNi SMAs a modern Nd:YAG laser was used [9]: Results of a martensitic Ti-49.3at\%Ni alloy were presented earlier [10]. In this contribution we will focus mainly on the mechanical behavior of a Ni-rich TiNi SMA in the laser-welded state compared to the unwelded one. The pseudoelastic properties of the laser-welds were also investigated and already published elsewhere [11].

\section{EXPERIMENTAL}

TiNi sheet metal (Nitinol Devices and Components, Fremont, USA) about 500 $\mu \mathrm{m}$ in thickness was used throughout this investigation. The sheets were received in warm-rolled condition with thickness reductions of about $20-25 \%$. A composition of 48.4 at.\% Ti and 51.5 at.\% Ni and $100 \mathrm{ppm} \mathrm{Fe}$ and $830 \mathrm{ppm}$ $\mathrm{O}$ as the main impurities were determined by chemical analysis. Prior to any laser-welding or tensile

(1) Now at: EUROflex Schüssler GmbH, Kaiser-Friedrich-Str. 7, 75172 Pforzheim, Germany 
testing the material was heat-treated at $550^{\circ} \mathrm{C}$ for $10 \mathrm{~min}$. in air (called "base material" in the following and was named "reference material" in [11]).

Laser welding was performed using a Nd:YAG laser (Baasel Inc., model BLS 710) with a wavelength of the laser beam of $\lambda=1.064 \mu \mathrm{m}$ operating in pulse mode. The speed during welding was $180 \mathrm{~mm} / \mathrm{min}$. An Ar gas shield was applied to protect the molten zone from oxidization. In order to study the deformation behavior of the molten zone itself a particular specimens were prepared containing a set, $14 \mathrm{~mm}$ in width, of parallel laser-welds, $0.4 \mathrm{~mm}$ apart from each other, covering the entire gauge length of a tensile test specimen. These specimens are called "remolten" material in the following.

Round specimens with diameters of $4.5 \mathrm{~mm}$ were laser-cut directly from the sheets for differential scanning calorimetry. (DSC) measurements resulting in a mass of about $50 \mathrm{mg}$. The DSC curves were recorded in a temperature range from $-100^{\circ} \mathrm{C}$ to $+200^{\circ} \mathrm{C}$ with a heating/cooling rate of $10^{\circ} \mathrm{C} / \mathrm{min}$. In order to chèck any effect of the laser-cutting process on transformation temperatures a dense array of parallel slits was cut into one of the disk-shaped DSC specimens which reduced the specimen's weight to less than $50 \%$. No influence of laser-cutting on transformation temperature could be detected by DSC.

Tensile tests were carried out on an Instron machine (model 1362) at $\mathrm{ds} / \mathrm{dt}=1 \mathrm{~mm} / \mathrm{min}$. using a combined heating/ cooling stage which allowed test temperatures in the range from $-80^{\circ} \mathrm{C}$ up to $200^{\circ} \mathrm{C}$ with a stability of $\pm 0.5^{\circ} \mathrm{C}$. Forces up to $5 \mathrm{kN}$ and extensions up to $5 \mathrm{~mm}$ can be measured with accuracies of $\pm 1 \mathrm{~N}$ and $<0,01 \%$, respectively.

Specimens for tensile testing were laser-cut out of the sheets. Details of the specimen geometry and dimensions are given in Fig. 1.

The width of the molten zone $(\mathrm{MZ}=0.6 \mathrm{~mm})$ was measured by hardness indentations every $50 \mu \mathrm{m}$ across the weld. A heataffected zone of $1.8 \mathrm{~mm}$ in width could only be detected by welding as-received material without heat treatment and corresponds to $14.4 \%$ of the gauge length.

Transmission electron microscopy (TEM) was carried out using a Philips CM 30 ST at $200 \mathrm{kV}$ equipped with a doubletilt specimen holder and an energy-dispersive X-ray spectro-

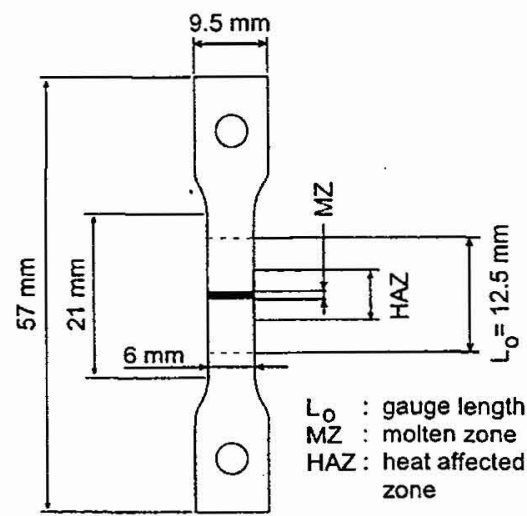

Figure 1: Geometry and dimensions of the tensile test specimens whîch were laser-cut out of $500 \mu \mathrm{m}$ sheets. meter. TEM specimens were prepared electrochemically using a solution of perchloric acid, ethylene glycol and methanol at a temperature of $-15^{\circ} \mathrm{C}$ in a Struers Tenupol 3 electropolishing device equipped with a Haake F3 cooling system.

\section{RESULTS}

The DSC curve of the base material is shown in Fig. 2. The onset temperatures of the different phase transformations are determined as the intersection of tangents to the slopes of a peak with the base line. A two-step forward transformation $B 2 \Rightarrow R \Rightarrow B 19^{\prime}$ was observed during cooling as expected with $\mathrm{R}_{\mathrm{S}}=8^{\circ} \mathrm{C}$ and $\mathrm{R}_{\mathrm{f}}=-12^{\circ} \mathrm{C}$ and $M_{S}=-43^{\circ} \mathrm{C}$ and $M_{f}=-81^{\circ} \mathrm{C}$ for the $\mathrm{R}$-phase and martensitic transformation, respectively. During heat-

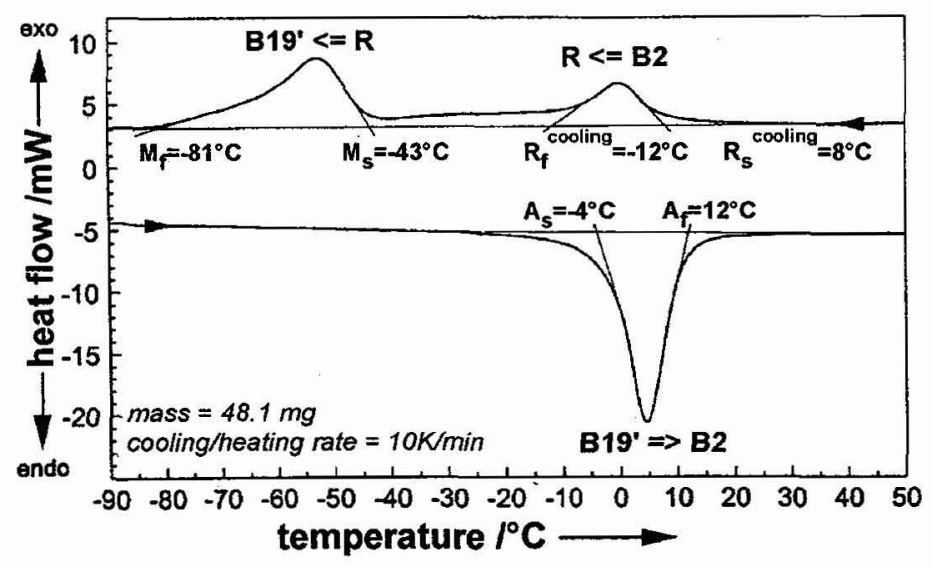

Figure 2: DSC curve of base material (subscripts "s" and " $\mathrm{f}$ " of the transformation temperatures denote "start" and "finish", respectively). 
ing the reverse transformation to austenite, $B 19^{\prime} \Rightarrow B 2$, took place with $A_{S}=-4^{\circ} \mathrm{C}$ and $A_{f}=12^{\circ} \mathrm{C}$. Only in uncompleted cycles the reverse transformation $\mathrm{R} \Rightarrow \mathrm{B} 2$ could be observed separately with $\mathrm{R}_{\mathrm{S}}$ heating $=1^{\circ} \mathrm{C}$ and $R_{\mathbf{f}}$ heating $=13^{\circ} \mathrm{C}$ (not shown in Fig. 2).

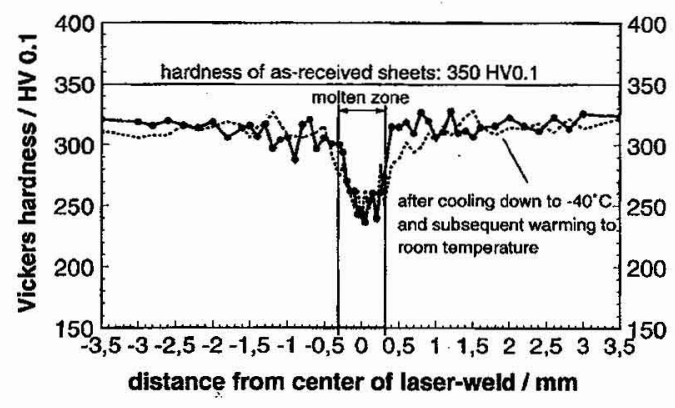

Figure 3a: Vickers hardness across a laser-weld of the base material as a function of the distance from the center of the weld.

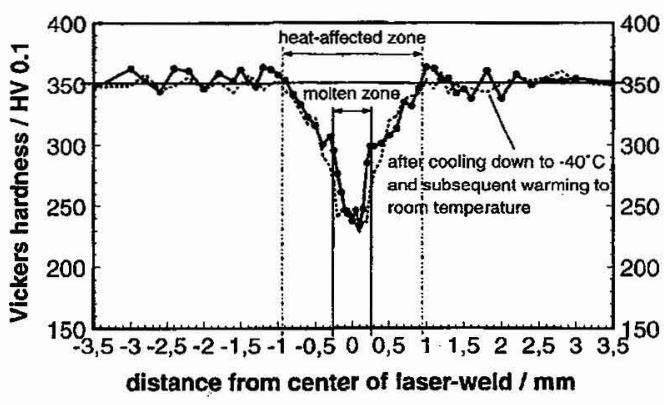

Figure 3b: Vickers hardness across a laser-weld of the asreceived material as a function of the distance from the center of the weld.

Vickers hardness values $\mathrm{HV}_{0.1}$ across the welds are plotted in Figures $3 \mathrm{a}$ and $3 \mathrm{~b}$. The base material exhibited a hardness of $315 \mathrm{HV}_{0.1}$ outside the welding area which is $10 \%$ less than the hardness of the asreceived state of the sheet metal $\left(350 \mathrm{HV}_{0.1}\right)$ prior to any heat treatment. Towards the molten zone (MZ) the hardness steeply decreases to values of about $250 \mathrm{HV}_{0.1}$ (Fig. 3a) without any noticeable heat-affected zone (HAZ). Laser-welding of the as-received material, however, leads to a extended HAZ of about $1.9 \mathrm{~mm}$ (Fig. 3b). In both cases of the base and the as-received material a cooling of the specimen to $-40^{\circ} \mathrm{C}$ after laser-welding and subsequent warming up to room temperature followed by the hardness measurements did not influence the Vickers hardness as shown by the dotted lines in Figures $3 a$ and $3 \mathrm{~b}$.

Tensile testing was used to study the mechanical behavior of laser-welded material in comparison with base material (Fig. $4 \mathrm{a}$ and $4 b)$. Stress-strain curves at various temperatures, namely $\mathrm{T}=-40^{\circ} \mathrm{C}$, room temperature $\left(\mathrm{T}=20^{\circ} \mathrm{C}\right)$ and $\mathrm{T}=110^{\circ} \mathrm{C}$, were recorded in order to investigate the material in its martensitic, pseudoelastic and austenitic state, respectively. Fig. 4 a displays the stress-strain curves for the base material. At room temperature $\left(\mathrm{T}=20^{\circ} \mathrm{C}>\mathrm{A}_{f}\right)$ the base material exhibits a pseudoelastic plateau up to strains of about $6 \%$ due to the formation of stress-induced martensite (SIM) as expected. The plateau stress during that strain regime is in the range of $400-425 \mathrm{MPa}$ and fairly constant. Beyond $6 \%$ strain the SIM is elastically deformed (to about $7 \%$ total strain). There-

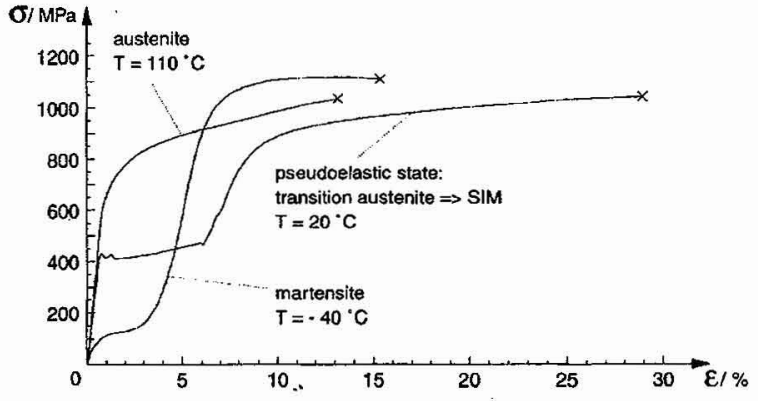

Figure 4a: Stress-strain curves of the base material for different temperatures.

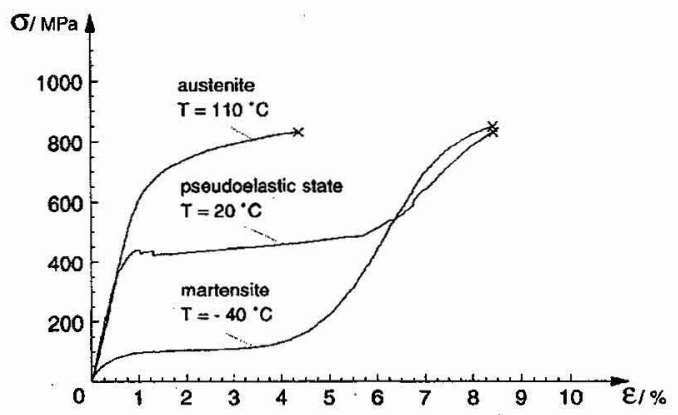

Figure 4b: Stress-strain curves of laser-welded specimens for different temperatures; note the different scaling of the strain axis compared to Figure 4 a. 
after, plastic deformation occurs up to an elongation to fracture of $29 \%$. An ultimate tensile strength of $1051 \mathrm{MPa}$ could be achieved at room temperature. Tensile tests at different temperatures revealed $\mathrm{M}_{\mathrm{d}}$, the maximum temperature at which martensite could be stress induced, to be $105^{\circ} \mathrm{C}$. As a consequence tensile testing of the austenite was performed at $110^{\circ} \mathrm{C}$. The corresponding stress-strain curve (Fig. 4a) shows an ultimate tensile strength of $1025 \mathrm{MPa}$ at an elongation to fracture of $13 \%$. Young's modulus of the austenite was determined to be $75 \mathrm{MPa}$ and thus slightly higher than for the pseudoelastic state at room temperature $(70 \mathrm{MPa})$. In both cases no local reduction in area was observed up to failure. Since DSC results showed the martensitic transformation to be completed at $\mathrm{M}_{\mathrm{f}}=-81^{\circ} \mathrm{C}$ (cf. Fig. 2), the specimens were cooled down to $-90^{\circ} \mathrm{C}$ prior to tensile testing of the martensitic state at $\mathrm{T}=-40^{\circ} \mathrm{C}$. Deformation of martensitic twins up to a total strain of $5.5 \%$. was followed by plastic deformation of the martensite up to a tensile strength of $1120 \mathrm{MPa}$. Thereafter local reduction in area was detected up to an elongation to fracture of $15 \%$.

Figure $4 \mathrm{~b}$ shows the corresponding three stress-strain curves for laser-welded specimens at the same temperatures as in Fig. 4a. Note the different scales of the axis compared to Fig. 4a. Ultimate tensile strengths in the range $800-850 \mathrm{MPa}$ were measured for the three temperatures $-40^{\circ} \mathrm{C}, 20^{\circ} \mathrm{C}$ and $110^{\circ} \mathrm{C}$. In order to get more significant values the pseudoelastic state was tested with 10 different specimens resulting in an average ultimate tensile strength of $823 \mathrm{MPa}$ with a standard deviation of $\pm 53 \mathrm{MPa}$. Therefore, laser-welded specimens exhibit $80 \%$ of the ultimate strength of the base material. The mean value of the elongation to fracture amounts to $8.4 \pm 0.6 \%$.

Plastic deformation starts beyond strains of about $7 \%$. Fracture always occurred at the welds for all testing temperatures.

For convenience, the stress-strain curves at $20^{\circ} \mathrm{C}$ of base and laser-welded material are replotted in Fig. 5 together with the data for a completely "remolten" specimen. Apart from a smaller elongation to fracture of the laserwelded specimen, the two curves of base material and laser-welded specimen are almost identical. The "remolten" state, however, exhibits a pronounced decrease in loading plateau stress and an increased irreversible strain after unloading [11].

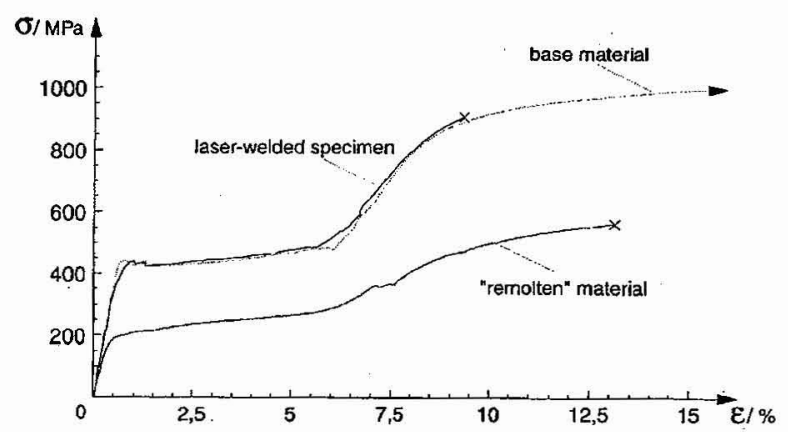

Figure 5: Stress-strain curves of base material (Fig. 4a), laser-welded specimen (Fig. 4b) and "remolten" material at $20^{\circ} \mathrm{C}$.

In order to get a deeper understanding of the deformation process the microstructure of laser-welds was investigated by light microscopy (LM) and TEM. Outside the heat-affected zone and in the base material the average size of the austenitic grains is about $15 \mu \mathrm{m}$. Towards the molten zone of laser-welded specimens a small region of recrystallization is followed by a columnar structure. The center of the molten zone exhibits large grains. No precipitates of $\mathrm{Ti}_{2} \mathrm{Ni}$ phase could be detected by $\mathrm{LM}$ at the grain boundaries inside the molten zone in contrast to a Ti-rich TiNi SMA [10].

TEM investigations revealed that the $\mathrm{Ni}_{4} \mathrm{Ti}_{3}$ precipitates of the base material are completely dissolved in laser-welded specimens as well as in the "remolten" material. TEM specimens of laser-welds showed a high density of small dislocation loops which results in a grainy contrast in bright field micrographs (Fig. 6a). At the grain boundaries of the austenitic B2 grains small $\mathrm{Ti}_{2} \mathrm{Ni}$ precipitates $(<200 \mathrm{~nm})$ were observed. Inside the grains sometimes tiny $(<100 \mathrm{~nm})$ inclusions were detected. EDX measurement revealed an enrichment in $\mathrm{Ti}$ content of these inclusions but their nature is yet unclear and will be investigated in detail in the near future. The "remolten" material also contains these inclusions. No dislocation loops, however, were observed. The dislocations are mainly glissile and lie on $\{110\}_{\mathrm{B} 2}$ glide planes (Fig. 6b). As in the laser-welded specimens the "remolten" material also exhibits only a few $\mathrm{Ti}_{2} \mathrm{Ni}$ precipitates. 


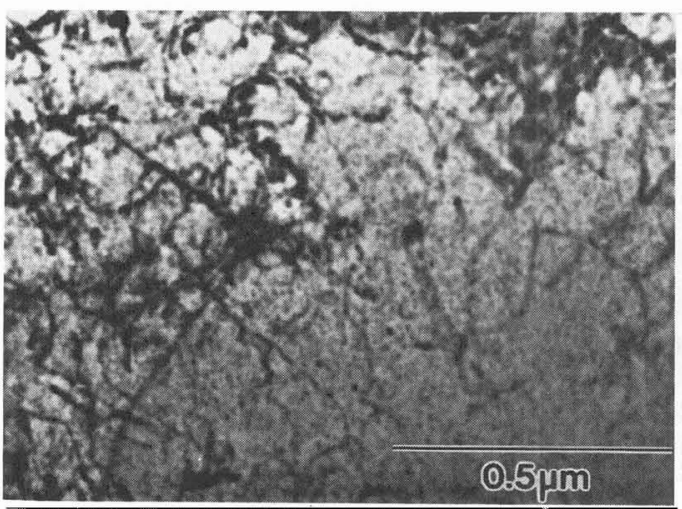

Figure 6a: TEM bright-field micrograph of the molten zone of a laser-welded specimen.

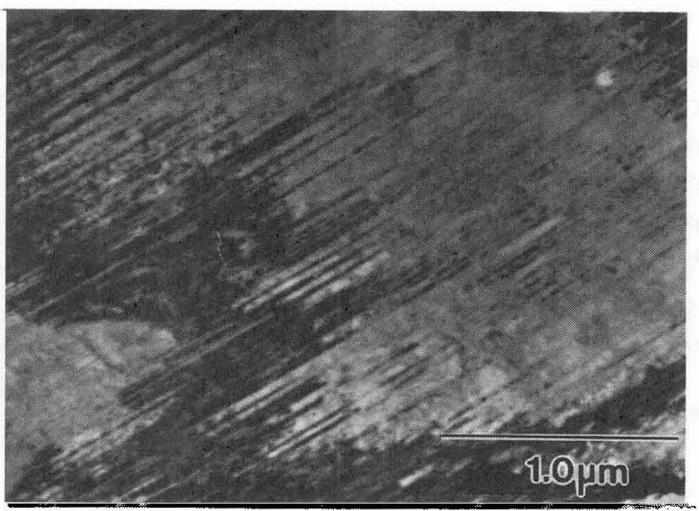

Figure 6b: TEM bright-field micrograph of the "remolten" material.

Fracture surfaces of base material anu laser-welded specimens were investigated by scanning electron microscopy (SEM). Both the base material and the laser-welded specimen showed ductile failure with fracture across the grains. No brittle part could be observed in both kinds of specimens. The base material contained small $(0.5 \mu \mathrm{m}) \mathrm{Ti}_{2} \mathrm{Ni}$ precipitates whereas the fracture surfaces of laser-welded specimens were perfectly free of any kind of particles and exhibited the typical appearance of ductile fracture (Fig. 7)

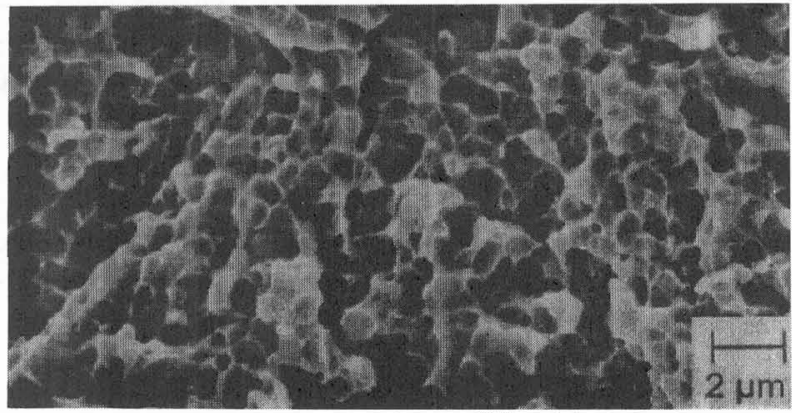

Figure 7: Ductile fracture surface of a laser-welded specimen.

\section{DISCUSSION}

The DSC measurement of the base material revealed the well-known two-stage martensitic transformation $B 2 \Rightarrow R=>B 19^{\prime}$ typical for slightly Ni-rich TiNi SMAs. Since $A_{f}$ temperature was about $12^{\circ} \mathrm{C}$, a pseudoelastic behavior was expected at deformation at room temperature (Fig. $4 \mathrm{a}$ and $4 \mathrm{~b}$ ). Both base material and laser-welded specimens exhibit a pronounced stress plateau upon loading up to strains of about $6 \%$. Both stress-strain curves are almost identical apart from a different elongation to fracture (Fig. 5). At $110^{\circ} \mathrm{C}$ and $-40^{\circ} \mathrm{C}$ both types of specimens reflect their austenitic and martensitic condition, respectively.

Vickers hardness measurements across the laser-welds clearly resolved the molten zone (Fig. $3 \mathrm{a}$ and 3b). The non-visibility of a heat-affected zone in the heat-treated $\left(550^{\circ} \mathrm{C} / 10 \mathrm{mini}\right)$ base material (Fig. 3a) can be understood: by this heat treatment hardness drops to a value which corresponds to roughly the one achieved in the heat-affected zone nearby the weld. Therefore an influence of laser-welding on hardness is detectable solely in the as-received material without thermal treatment after rolling.

An embrittlement of the welding zone due to a dendritic microstructure [3-6] predicted for all joining techniques which produce a molten zone could not be confirmed. Contrarily, stress-strain curves, a missing of local reduction in area during deformation and the results of the microstructural investigations showed ductile behavior up to fracture. However, by severe heat impact by many parallel laser-welds the ultimate tensile strength decreases to only $550 \mathrm{MPa}$ compared to $1021 \mathrm{MPa}$ and $820 \mathrm{MPa}$ for the base material and the laser-welded specimens, respectively. A single laser-weld melts only $0.6 \mathrm{~mm}$ of the material. A heat-affected zone could not be detected in hardness measurement as stated above. A set of parallel welds, however, $0.4 \mathrm{~mm}$ apart from each other means that $3 / 4$ of the material is molten twice every laser-weld is thermally treated at least by four neighboring welds. The effect of twice remelting the 
material and thermal treatment by neighboring welds can directly be observed in TEM. A high density of glissile dislocation on $\{110\}_{\mathrm{B} 2}$ planes facilitates further deformation and yield stress decreases as a consequence. A single laser-weld, on the other hand, leaves behind dislocations not only on glide planes due to the rapid solidification from the melt. These partly sessile dislocation in combination with many small dislocation loops acting as obstacles to the dislocation motion keep the strength of the laser-welded material on a high level. As a consequence, however, the ductility is decreased in comparison with the base material.

The ultimate strength of the laser-welded joints amounts to $80 \%$ of the base material not affected by the test temperature. This is exactly the same as reported for resistance butt welding of a Ti-50.0at.\% Ni SMA [5]. Therefore, laser-welding using modern laser systems is an alternative which offers much more freedom concerning weldable geometries.

\section{CONCLUSIONS}

Investigations of mechanical behavior and microstructure of a laser-welded Ti-51.5at.\%Ni SMA clearly demonstrated that pseudoelastic stress plateaus upon loading identical to the base material can be achieved. Ultimate tensile strengths of $80 \%$ of the base material and elongations to fracture of $8.4 \%$ ensure the full use of SIM formation in laser-welded components.

\section{Acknowledgments}

The authors are grateful to T. Stober for TEM specimen preparation, to B. Rabsch and H. Besser for their assistance during metallographic work and laser-welding and to Dr. Chr. Adelhelm for performing the chemical analysis of the material's composition.

\section{References}

[1] Shinoda T., Tsuchiya T., Takahashi H., Quarterly J. Japan Welding Society (1991) 9-14.

[2] Shinoda T., Tsuchiya T., Takahashi H., Trans. Japan Welding Society 22 (1991) 30-36.

[3] Beyer J., Hiensch E.J.M., Besselink P.A., "Resistance Welding of TiNi-Shape Memory Alloys", The Martensitic Transformation in Science and Technology, E. Hornbogen and N. Jost Eds. (DGMVerlag, Oberursel, 1989) pp. 199-206.

[4] Beyer J., Besselink P.A., Lindenhovius J.H., "Shape Memory and Microstructure of Welded TiNi Alloy", Proc. Shape Memory Alloys 1986, Guilin 1986 (1986) pp. 492-497.

[5] Nishikawa M., Tanaka H., Kohda M. Nagaura T., Watanabe K., J. Phys. Colloq. C4 (1982) 839-844.

[6] Jackson C.M., Wagner H.J., Wasilewski R.J., NASA report \#SP 5110 (NASA, Washington D.C., 1972) p. 22.

[7] Hirose A., Uchihara M., Araki T., Honda K., Kondoh M., J. Japan Inst. of Metals 54 (1990) 262-269.

[8] Araki T., Hirose A., Uchihara M., Kohno W., Honda K., Kondoh M., J. Soc. Mater. Sci., Japan, 38 (1989) 478-483.

[9] Haas T., "Laserstrahl-Schweißen von NiTi-Formgedächtnislegierungen", $\mathrm{PhD}$ thesis, Universität Karlsruhe 1996 (Forschungszentrum Karlsruhe GmbH, Karlsruhe, 1996), report \# FZKA 5709 (in german).

[10]Schloßmacher P., Haas T., Schüßler A., "Laser Welding of Ni-Ti Shape Memory Alloys", First International Conference on Shape Memory and Superelastic Technologies (SMST 94), Pacific Grove 7-10 March 1994, A.R. Pelton, D. Hodgson, and T.W. Duerig Eds. (SMST International Committee, Monterey, 1995) pp. 85-90.

[11]Schloßmacher P., Haas T., Schüßler A., "Laser-welding of a Ni-rich TiNi shape memory alloy: pseudoelastic properties", Second International Conference on Shape Memory and Superelastic Technologies (SMST 97), Pacific Grove, 3-6 March 1997 (in press). 